\title{
Market Behavior of Knowledge Consumption and the Development Strategy in the Era of Digital Economy
}

\author{
Xinhang $\mathrm{Yu}^{1, *}$ \\ ${ }^{1}$ School of Finance, Yunnan University of Finance and Economics, Kunming, Yunnan 650221, China \\ "Corresponding author. Email: yuxinhangjq@126.com

\begin{abstract}
Knowledge consumption behavior is an important feature of the digital economy era. Consumers' knowledge anxiety, user learning behavior, and the networked crowd structure have expanded the demand for knowledge. Technological innovation and participatory production have improved the ability to generate knowledge. The payment trading platform has played a role in chain extension, credit enhancement and efficiency enhancement. The reputation control mechanism and quality assurance mechanism of the platform and the education for consumers are conducive to resolving the effects of knowledge heterogeneity and information asymmetry in transactions.
\end{abstract}

\section{Keywords: digital economy, knowledge consumption, knowledge payment, market behavior}

\section{INTRODUCTION}

Digital economy refers to a series of economic activities that use digital knowledge and information as key production factors, modern information network as an important carrier, and effective use of information and communication technology as an important driving force for efficiency improvement and economic structure optimization. In the era of digital economy, a large amount of data gushes out, which makes the ability of human beings to store, calculate, analyze, mine, exchange, process, utilize and develop data improved in an all-round way, and thus leads to a revolution of data technology represented by big data, cloud computing, artificial intelligence, mobile communication, block chain, etc. This kind of revolution has brought about a new breakthrough in people's thinking, concepts and methods of understanding the world. Digital economy has become a new form of social economy after agricultural economy and industrial economy. In the era of agricultural economy, land is the most important factor of production. In the era of industrial economy, capital market is the most important factor of production, and capital is the main driving force of economic growth. In the era of digital economy, knowledge becomes the main factor of economic growth. Knowledge production, innovation and search, trade and consumption have become important economic forms in the era of digital economy.

Among the early researches, whether it is Von Hayek's division of knowledge (1937), Machlup's knowledge industry (1962) or Boulding's knowledge economics (1966), knowledge is used as a resource, emphasizing the effect of knowledge input on economic growth. OECD (1996) held the same view, emphasizing the economic role of knowledge in production, distribution and use. APEC (2000) emphasized the role of knowledge in production, distribution and use in the growth, wealth creation and employment of all industries. The development of knowledge industry and the formation of knowledge market reflect the important role of knowledge as a resource. At this time, the knowledge market is mainly the trading market of intellectual property, and knowledge pricing is also the pricing behavior in different market structures in the traditional market resource allocation. After the mid1990s, especially in the 21st century, with the widespread popularity of the Internet and the flattening of social structure, knowledge sharing began to enter people's daily life rapidly. Everyone starts to be the producer, creator and consumer of knowledge. Knowledge consumption is not only an activity of ivory tower, but also a universal knowledge feast. Knowledge is not only a factor of production, but also a common consumption goods. The cost of creating new knowledge is extremely high. Once knowledge is created, its marginal production cost is extremely low or even zero (Harris, 2001). In the era of zero marginal cost, many knowledge consumption is almost provided free of charge. In China, knowledge consumption enters the period of sharing and free of charge around the year of 2010. However, with the arrival of the digital economy era, data and information grow exponentially, knowledge and information are uneven, and the free model without knowledge innovation incentives is unsustainable. Since 2016, knowledge payment, a new form of knowledge consumption, has developed rapidly in China and has become the mainstream form of knowledge consumption. Knowledge economy 
develops rapidly from knowledge production, exchange and distribution to knowledge consumption. Knowledge economy develops from knowledge innovation and production to the golden stage of knowledge consumption.

Therefore, the study of the characteristics and internal logic of knowledge consumption market in the era of digital economy will help to clarify the essence of knowledge consumption market, promote the sound development of knowledge consumption market and realize the value of knowledge.

\section{KNOWLEDGE CONSUMPTION AND ITS EVOLUTION}

Knowledge is the information expression of ideas. Knowledge consumption is the continuation of knowledge production and knowledge exchange, and is the process of acquiring and using knowledge driven by interests. According to the classic definition of knowledge put forward by Plato in "Theaetetus", knowledge here is "the justified true belief". Most ideologists think that knowledge must have three characteristics of being justified, true and believed. According to Webster Dictionary, knowledge refers to the sum of human knowledge and experience about nature and society. It includes data, information, knowledge and wisdom. Data is a series of facts of external environment, which are unorganized numbers, words, sounds and images. Information refers to data flow with timeliness, processing and certain meaning and logics. Knowledge is the instructive structured information deposited by induction and deduction of information. Wisdom is the ability to use existing knowledge to analyze, compare and deduce solutions for problems in the development of the material world. In the era of digital economy, with the application of modern information technology, massive data and information will be generated and further evolved into knowledge and problem-solving wisdom. However, it is generally believed that knowledge is scattered among individuals, and no individual or organization can master all the knowledge of effective economic operation (Von Hayek, 1937, 1945). The information gap between relatively "certain" individual knowledge and the living environment full of "uncertainty" is the fundamental driving force for the social evolution of human beings (Heiner, RA. 1983). Modern information technology provides convenience for knowledge acquisition, storage, application and sharing.

Knowledge has the dual attributes of private products and quasi public products. In the field of knowledge consumption, there are also free acquisition of knowledge (such as news, etc.) and paid consumption. In China, knowledge sharing and free is still the main body in the field of online knowledge consumption before 2016. It is obvious that the knowledge consumption mode without knowledge innovation incentive is not sustainable. In March 2015, Guokr launched the content of "being expert at sth.", and the concept of knowledge payment appeared for the first time in China. At the end of 2015, Luo Zhenyu's "logical thinking" app was released. And then, Fenda, Himalaya, Zhihu live, etc. became the best in the knowledge payment market. After that, many knowledge communities, social products, music platforms and news media have launched their own knowledge payment columns, covering vocational skills, investment and financial management, health, law, early childhood education, emotional psychology, financial management, lifestyle, literature, film, art, sinology, social science and other fields. According to the report issued by a securities company, the group size of knowledge payment is expected to reach 410 million people in 2020, and the income scale can reach 39 billion yuan. More and more industries participate in knowledge dissemination, and the industrial chain derived from knowledge payment industry is becoming more and more perfect and extended.

In fact, knowledge payment has existed since ancient times. In ancient times, it was manifested in the behavior of going to schools, hiring famous teachers, purchasing books and so on. Due to the different influence of knowledge carriers, in the period of the dissemination of handwritten and oral knowledge, the cost of knowledge consumption is high, there is subjectivity and randomness in the dissemination, and knowledge consumption is only the rights of a few people. The invention of printing greatly reduces the cost of knowledge dissemination, and more people join in the knowledge consumption. At the same time, printing also makes people's way of thinking have revolutionary changes. The author's immutability and authority are reflected. People begin to pay more attention to the authors and worship the authors rather than the text. In the thousands of years, books, as the medium of knowledge dissemination, enable knowledge to be mass produced and disseminated like standardized industrial products. Later, newspaper media, radio media and television media also have this feature. At this time, the relationship between the author of the book and the reader is a separate, nondialogic and one-way media communication mode, which is more manifested as a self-examination mode of self-talk. In addition, the spread of specialized education knowledge in universities is also bound in a set of ivory tower discourse system, which is forbidden to outsiders. Only those who have fully obtained peer review can stand on the stage. In the age of handmade and parchment, knowledge production is expensive, but knowledge consumption is free of charge. In the age of industrial economy, the dissemination of knowledge is open, but the knowledge consumption needs to be paid. 
In the era of digital economy, modern information technology has once again brought about revolutionary changes in knowledge consumption. Network knowledge payment is constantly challenging the traditional knowledge consumption mode, bringing a series of changes in knowledge production and dissemination. Knowledge consumption has been transformed from the long-sequence knowledge of the original integrated professional ideas into the short and fragmented experience opinions and expression, from the production of specialized knowledge to the participatory production of audience groups, from the traditional linear communication to the interactive communication of network media, and the pattern of knowledge communication in the era of digital economy has changed substantially.

\section{ANALYSIS ON MARKET BEHAVIOR OF KNOWLEDGE CONSUMPTION IN THE ERA OF DIGITAL ECONOMY}

In the knowledge consumption market, it is necessary to understand the demand behavior of knowledge consumption, the generation logic of knowledge consumption and the role of transaction service platform, so as to better understand the market behavior.

\section{A. Knowledge consumption demand behavior}

1) Knowledge anxiety caused by information overload and filtering failure: The digitalization of knowledge and information promotes the diversification and openness of knowledge dissemination, but also creates a network cultural environment of information overload. Although the audience can accept knowledge and information anytime and anywhere, the serious overload of information makes it difficult for consumers to obtain effective knowledge. The constant refresh of Internet massive data causes consumers' anxiety about information throughput. This situation reflects the objective existence of information filtering failure in the network information overload environment. According to Shirky C, an Internet scholar, people's sense of information overload does not come from information overload, but from information filtering failure. The old filter is the check behavior of knowledge managers such as book editors. However, in the new Internet mode, the lack of effective information filter leads to filter failure, knowledge anxiety of consumers, and also stimulates the demand for highquality information and knowledge.

2) User learning and consumption upgrading behavior: Since ancient times, human beings have produced knowledge because of survival and competition, triggering the demand for learning. In the information society, the demand for learning of the public is growing rapidly, and the way to acquire knowledge through the network has become the mainstream. The upgrading of consumption structure has increased the proportion of cultural consumption of consumers, and the change of mobile Internet has made consumers have the conditions to invest more income and time in the consumption of spiritual life. With the change of industrial structure, it has higher requirements on labor force, and the growth of whitecollar class has laid a larger market scale for the demand side of knowledge payment.

3) Network population structure behavior in the era of digital economy: In the era of digital economy, the network population structure has formed a large number of knowledge needs, and changed the consumption mode formed in the industrial era from multiple perspectives. In the digital economy, consumers have evolved from the physical aggregation with the city center as the core to the network aggregation with the network space as the center. Consumers who are dispersed in the network space believe in the information of the neighboring network nodes, and are more susceptible to the influence of the neighboring network nodes than the center of the traditional tree structure. In the digital economy, consumer behavior changes from functional consumption to data consumption or functional consumption plus data consumption, from one-time consumption to continuous consumption, from individual consumption to community consumption. On the one hand, the network population structure expands the number of knowledge consumers, enhances the trust and recognition within the network nodes, and also strengthens the learning behavior of individuals to the excellent individuals in the group, forming a large number of knowledge consumption needs.

\section{B. The logic generated from knowledge consumption}

1) Technological innovation is the foundation of network knowledge consumption: The changes caused by network technology have increased the opportunities of knowledge generation for the general population, the popularization of communication subjects and the fragmentation of knowledge generation, formed a wave of knowledge sharing based on knowledge surplus, and realized the large-scale dissemination of knowledge.

2) Audience participation production blurs the boundary between knowledge producers and consumers: In the age of traditional media, knowledge consumers acquire knowledge value through independent reading. In the age of Internet, knowledge consumers are not 
only consumers, but also producers of knowledge communication. Audience participation in content production has become an important feature of Internet knowledge payment communication.

\section{The role of knowledge consumption trading platform}

1) The chain extension role of payment trading platform: The essence of knowledge payment is to turn knowledge into products or services to realize business value. Viewing from a deeper perspective, the underlying logic of knowledge payment is actually to establish links between people and knowledge, knowledge and platform, and between people. Knowledge payment platform can increase the breadth and depth of platform connection through platform ecology, increase platform traffic and improve platform value by connecting various mobile terminal devices.

2) Credit enhancement function of payment trading platform: Through the payment trading platform, people can reduce the information gap between the supply and demand of knowledge consumption, improve the trust and identity of knowledge providers, and improve the trust and identity of consumer channels.

3) The payment system of the payment trading platform helps to improve the conversion rate of users: The payment system of online knowledge payment platform is the key factor of user conversion rate. A smooth payment experience and simple payment path will speed up the decision-making time of users' purchase, improve the conversion rate from decisionmaking to payment, and reduce the loss of users.

\section{Formation of market value of knowledge consumption}

1) The difference of property right system arrangement in digital economy is the basis of the formation of different intellectual product price: In the digital economy, data has become a key factor of production driving the economic operation. Data analysis based on various information flow platforms can realize the value-added of knowledge.

As a factor of production, data is very different in the arrangement of property right system. As a resource, data is basically between pure public goods and private goods in the arrangement of property right attributes, which belongs to quasi public goods. Therefore, its pricing basis and price operation mechanism are totally different from other factors of production. The property ownership is weakening in the digital economy. This shows that the property ownership of digital products is disappearing. Digital products are stored and transmitted in the form of bits on Internet terminal devices. And digital products can be copied at zero or very low cost after production, with the characteristics of unlimited supply, which is completely non-exclusive, that is, one consumer does not exclude other consumers from using their products or services. Therefore, consumers don't care who these products belong to, but whether their consumption function can be realized. In this case, the ownership attribute of digital products (knowledge, music, books, videos, etc.) basically disappears.

2) In the era of digital economy, knowledge value innovation has advantages of late development: The biggest difference between the digital economy and the traditional real economy is that the increasing marginal return will lead to the later advantage. In the characteristic range of digital economy, it shows that in the process of knowledge innovation, as the scope of knowledge application gradually expands, the number of customers involved will also increase, and in this process, the value created by digital products will be more.

3) The value of knowledge comes from the future value of its learning: Knowledge is the process of learning, and its value comes from the effect of learning; the cognition of the future comes from the input of past information, so its value comes from the value of future information and the cost of present information input.

\section{THE DEVELOPMENT STRATEGY OF KNOWLEDGE CONSUMPTION MARKET}

Due to the lower threshold of knowledge production and communication and the sharp increase of communication channels, it is difficult for consumers to judge the real market situation, and the "lemon market" effect further increases this result, which makes the lack of effective and high-quality knowledge and information, and ultimately cannot meet the needs of consumers.

Speaking to the reasons, firstly, knowledge is a kind of information expression of individual ideas, which needs other people's experience and confirmation, but the difference of individual cognition may lead to the deviation of this external sense of identity, which reduces the satisfaction of knowledge consumers. Secondly, in the knowledge market, the complementary characteristics of knowledge mean that the value of a knowledge segment is closely related to other knowledge segments. This requires that both sides of knowledge transaction must have certain common recognition in experience and cognition, and the private information transaction which is lack of other people's experience may be too expensive to complete. Thirdly, the identity of knowledge providers is not easy to identify, which leads to information asymmetry and 
reduces the selectivity of knowledge consumers. Fourthly, the apriority of knowledge transaction makes the quality of knowledge transaction impossible to be tested in advance, and when the buyer has the information he has bought, he is no longer willing to buy. Generally speaking, the heterogeneity of knowledge and the information asymmetry between the two parties may lead to the instability of knowledge consumption market and the decline of transaction quality. Therefore, in order to make the consumer knowledge trading market on a sound development path, it is necessary for the trading platform to strengthen market construction from three aspects: market trading mechanism, knowledge provider reputation, knowledge consumer education, and give full play to the role of the trading platform in supervision and guidance.

The first is to introduce reputation mechanism. It is necessary to to establish a credit display mechanism through various credit evaluation, knowledge provider credit rating, external credit enhancement and other ways to improve the credibility of knowledge trading providers. At the same time, it is better to establish incentive mechanism and dishonesty and false punishment mechanism to ensure the effectiveness of the whole reputation mechanism.

Second, it is required to increase the education for knowledge consumers. It can increase the communication between knowledge providers and knowledge consumers through free, public welfare and online communities, so as to improve the collective identity within the group and reduce the cognitive bias.

The third is to increase the construction and experience of platform informatization, improve the reputation and market efficiency of the platform, establish industrial coordination mechanism, and improve the stability of the industry.

\section{CONCLUSION}

Knowledge is a kind of information expression of ideas. The information difference between individuals and organizations becomes the power source of knowledge transaction. Digital economy makes people's thoughts, ideas and methods of understanding the world have a new breakthrough development. Various ideas and methods not only affect production activities as a resource, but also play an important role in consumption activities. Knowledge consumption behavior is an important feature in the era of digital economy. In the activity of knowledge payment consumption market, it is necessary to grasp the internal logic of knowledge generation and knowledge demand, understand the value and role of knowledge trading platform, introduce reputation control mechanism and quality assurance mechanism in knowledge trading, increase consumer education and group identity, and improve the stability and trading quality of knowledge consumption market.

\section{References}

[1] Von Hayek, F. A. (1937),"Economics and knowledge", Economica 4(13): 33-54

[2] Machlup, F. (1962), The Production and Distribution of Knowledge in the United States,Princeton University Press.

[3] Boulding,K.E.(1966),"The economics of knowledge and the knowledge of economics",American Economic Review 56(1/2):(2)1-13.

[4] OECD(1996), The Knowledge-Based Economy,OECD Publishing

[5] APEC(2000), Towards Knowledge-based Economies in APEC,APEC Publishing.

[6] Von Hayek,F.A.(1945),"The use of knowledge in society",American Economic Review 35(4): 519-530.

[7] Heiner, $\mathrm{R}$ A. The origin of predictable behavior[J].The American Economic Review，1983， 73 (4) : 560-595.

[8] Shirky, C. Here Comes Everybody. The Power of Organizing without Organizations; Penguin: New York, NY, USA, 2008

[9] Zhu Yan, Shi Yan. Analysis on elements of digital economy [J]. Tsinghua Business Review, 2019(Z2): 24-29. (in Chinese)

[10] Zhang Lizhe. Analysis on the difference between digital economy and real economy evaluation [J]. Reform and Opening, 2018(24): 37-39. (in Chinese)

[11] Yi Xianrong, Chen Yingying, Wei Yushuang. Research on Several Major Theoretieal Issues about the Digital Economy Based on the General Analysis of Modern Economics [J]. Abstracts of Social Sciences, 2019(9): 41-43. (in Chinese)

[12] Zhang Sheng, Chang Jiangbo. Research on the governance mechanism of knowledge-paying "lemon market" [J]. Commercial Research, 2018 (11): 97-107. (in Chinese)

[13] Dai Ming, Chen Jun, Chen Jingxin. Knowledge Economics: A Review of 50 Years and Prospect $[\mathrm{J}]$. Economics Information, 2016 (12): 4-13. (in Chinese)

[14] Sun Jia, Yan Dingyou. A review of the generation logic, content production and value of online knowledge payment $[\mathrm{J}]$. China Publishing Journal, 2019 (1): 31-34. (in Chinese)

[15] He Yi, Liu Yanzhi, Wang Zheng. How Is Knowledge-Payment Possible?-From the Behavioral Economic Perspective $[\mathrm{J}]$ Library Tribune, 2020, 40(3): 47-54. (in Chinese)

[16] Shen Junhan, Zhou Maojun. Market logic and development strategy under the knowledge payment model [J]. China Publishing Journal, 2019 (7): 38-42. (in Chinese)

[17] Hu Yong, Cui Chenfeng, Wu Jiajie. Content payment: a new kind of content economics [J]. News and Writing, 2019 (2): $27-$ 35. (in Chinese)

[18] Yu Wenwen, Song Peiyi. Research on Value Chain System of Online Knowledge Payment Platform [J]. Media, 2019 (7): 91 93. (in Chinese) 